\title{
Students' Perceptions of Learner-Learner Interactions that Weaken a Sense of Community in an Online Learning Environment
}

\author{
Krystle Phirangee \\ University of Toronto
}

\begin{abstract}
Despite the growth of its popularity in recent years, online learning has demonstrated high dropout rates compared to dropout rates in traditional face-to-face courses. Prior research attributes attrition to the physical isolation of students from one another and the lack of interaction between and among them-factors which foster feelings of alienation, isolation, and disconnection. The goal of this research study was to more deeply understand the causes of such negative feelings, which may eventually lead students to drop out of online courses. More specifically, this study adopted a qualitative approach by interviewing six graduate students to further explore which specific learner-learner interactions weaken online students' sense of community. Seven learner-learner, interactions were identified: the keener, lack of meaningful data, selective listening, lack of attribution, going off on tangents, editing notes, and cultural exclusion.
\end{abstract}

Keywords: online learning, learner-learner interaction, dropout/retention

\section{Introduction}

Over the past several years, online learning has grown in popularity among learners. A report sponsored by Pearson and the Online Learning Consortium revealed that online enrollment rose by 570,000 students in the past year to 6.7 million students in the U.S., and that 32 percent of all college and university students were enrolled in at least one online course 
(Allen \& Seaman, 2013). Similarly, an Industry Canada report revealed rapid growth in distance education enrollment at the post-secondary level in Canada, with distance education course registrations increasing faster than on-campus course registrations (Hirshhorn, 2011). Although the online learning registration rate has slowed, it is not expected to decrease in the future because of the ever-present demand (Allen \& Seaman, 2013), making it a core feature in most universities and community colleges (Layne, Boston \& Ice, 2013; Sutton \& Nora, 2008).

Studies suggest that students are attracted to the convenience of online learning. Online courses can be accessed at any time from any place, allowing learners to work at their own pace (Bolliger \& Inan, 2012). In addition, because courses are accessible from anywhere, students have time to structure their courses around work and family responsibilities as they see fit (Bolliger \& Inan, 2012; Hara \& Kling, 2001). Other advantages include discussion forums in online courses, in which learners can share resources and engage in discourse without a need for turn-taking by participating in many discussions simultaneously, have greater access to others' ideas, and have with the opportunity to reflect on their ideas before sharing them publicly (Hewitt, 2005). These advantages have contributed to the explosive growth in distance education in recent years.

Unfortunately, as distance education becomes more popular, its problems have become increasingly more pressing. Most significantly, distance education tends to suffer from high dropout rates (Xu \& Smith-Jaggars, 2011). Interestingly, numerous researchers have investigated student learning in online and face-to-face courses and found that there were no significant differences (Bernard, et al., 2004; Russell, 2001). Despite these findings, the online learning literature consistently reports lower retention among students in online courses compared to their peers in traditional face-to-face courses (Fetzner, 2013). This has become a growing concern among academic leaders (Allen \& Seaman, 2013) because success is commonly reflected and measured according to an institution's student retention rate. For example, some scholars (Diaz, 2002) emphasize that high dropout rates are influenced by uncontrollable factors and should not solely be used as an indication of academic success or failure.

Problems with attrition have been attributed to the physical separation of students (Rovai, 2002a) and the lack of interaction between them (Carr, 2000). As Rovai (2002b) observes, "such separation tends to reduce the sense of community, giving rise to feelings of disconnection, isolation, distraction, and lack of personal attention” (p. 2). As some researchers suggest, students' feelings of isolation and disconnectedness are the main reasons they drop out of online course courses (Angelino, Williams, \& Natvig, 2007; Kanuka \& Jugdev, 2006). To understand the possible causes of such feelings, which eventually lead students to drop out of online courses, research has focused on student characteristics. For example, two studies found that community college students who took online courses were more likely to drop out than their peers in face-toface courses (Jaggars \& Xu, 2010; Xu \& Jaggars, 2011). In another study, difficult instructional materials and content has been cited as a possible reason students opt to drop out of online courses (Diaz, 2002); thus, the difficulty of a course may also be a factor of whether students drop out of an online course. Other research has found that a strong negative correlation existed between experience in a subject and dropout rates. This indicates that students are more likely to drop out of an online course if they are unfamiliar with a subject or if they are enrolled in a subject unrelated to their prior experience (Xenos, Pierrakeas \& Pintelas, 2002). In addition, 
"projections of social presence" [being perceived as a 'real person'] and "affective expression" strongly influence students' persistence in an online course (Boston, Diaz, Gibson, Ice, Richardson, \& Swan, 2009), perhaps because students who have a feeling of belonging to the online community are more likely to achieve success (Tu \& McIssac, 2002).

Some studies suggest that feelings of isolation and disconnection can be partially overcome by fostering a community, that is, a sense of belonging and interactivity among learners in an online course (Liu, Magjuka, Bonk, \& Lee, 2007; Ouzts, 2006; Rovai, 2002a; Thompson \& MacDonald, 2005), which is the definition of community adopted for this study. A community allows students to build camaraderie and engage in social reinforcement (Conrad, 2005; Gallagher-Lepak, Reilly, \& Killion, 2009). Many scholars argue that interaction is critical in building a class-wide community online (Arend, 2009; Song \& McNary, 2011; Stepich \& Ertmer, 2003; Swan, 2009) because it is thought to lead to deeper thinking (Hulon 2013; Larson \& Keiper, 2002) and better student outcomes (Drouin, 2008; Exter, Korkmaz, Harlin, \& Bichelmeyer, 2009; Liu et al., 2007). Thus, when a community is fostered, students are likely to interact with each other more often. Such interactions may contribute to the reduction of students' feelings of isolation and disconnection.

Much of the research that explored interaction has focused on its importance in helping to foster a sense of community among online learners (Conrad, 2005; Gallagher-Lepak, Reilly, \& Killion, 2009), as a critical component for online learning (Hillman, Willis, \& Gunawardena, 1994; Moore \& Kearsley, 1996; Zheng \& Smaldino, 2003), and necessary for student satisfaction within an online course (Berge, 2002; Northrup, 2002). However, Zembylas (2008) found that certain interactions also weaken students' sense of community. These interactions are more likely to happen when students struggle to find appropriate ways to communicate with their peers online, and may unintentionally cause some students to feel isolated and alienated (Zembylas, 2008). Consider this: A student posts a note in the online discussion forum with the hope that a peer will respond, but does not receive a response (Zembylas, 2008). Unfortunately, this unsuccessful gambit leads the student to think that the note has been ignored because it was not valuable to the discussion and the learning of others (Zembylas, 2008).

Interestingly, in another study conducted by Rovai and Wighting (2005), alienation and a sense of community have an inverse relationship. First, if students do not have the feeling of belonging, then their sense of community will weaken and the feeling of alienation will strengthen. Second, a sense of community is likely to weaken for learners if their cultural and personal beliefs clash with the perceived beliefs of the community because they will see themselves as different from their peers. Unfortunately, some students come to believe (perhaps falsely) that they would be ignored, rejected, or devalued by their peers if they share their beliefs publicly in the online discussion forum. Making such assumptions for certain types of interactions will lead to feelings of isolation and alienation among some online learners, which is worrisome, because some studies (Rovai \& Wighting, 2005) have found that such feelings not only weaken a sense of community, but also foster a negative online learning experience, potentially contributing to the high dropout rates in online courses.

According to Sharp and Huett (2005), "[t]here is simply not enough research to answer what type of interaction distance learners prefer or should be expected to engage in” (p.5). 
Furthermore, despite the view of interactions as a critical component for learning, the degree of its effect on learning is unclear (Kelsey \& D'souza, 2004; Reisetter \& Boris, 2004; Sabry \& Baldwin, 2003). Building on Sharp and Huett's (2005) comments, the purpose of this study was to contribute to this discussion and explore possible interactions that weaken a sense of community and cause students to feel isolated and disconnected from their peers in an online course. Specifically, the following research questions are explored: (1) What types of interactions weaken a sense of community in an online course? (2) How do these interactions affect students' perceived learning?

Teaching online is demanding and some instructors may struggle with sorting out what strategies and interactions are effective in an online learning environment. For example, teaching strategies used in face-to-face courses may be less effective and beneficial in online courses (Horspool \& Lange, 2012). If instructors understand which interactions lead to feelings of isolation and alienation, they might modify their instructional approaches to provide the appropriate support to maintain a strong sense of community among students. Furthermore, if students are aware of such interactions, they may avoid these interactions when participating in the online discussion forum, potentially minimizing high attrition rates. Instructors and students need to be aware of the factors and processes that can weaken a sense of community because if they are unaware they run the risk of unintentionally alienating others and triggering feelings of isolation and disconnection.

\section{Method}

This research adopted the qualitative grounded theory approach, which emerged from the work of sociologists Barney G. Glaser and Anselm L. Strauss (1967). Specifically, for Glaser and Strauss (1967) the main components of grounded theory include:

- Collecting and analyzing data concurrently.

- Developing codes from data rather than preconceived hypotheses from the literature.

- Consistently comparing the data during each stage of analysis.

- Redefining the theory during data collection and analysis.

- Using memo-writing to keep track of what is being learnt during analysis, which helps with elaborating on categories.

- Sampling for the purpose of constructing theory and not to represent the population.

- Conducting the literature review after the analysis.

It is important to mention that both Glaser and Strauss have taken their work on grounded theory in different directions (Charmaz, 2014; Kelle, 2005). Glaser remained consistent with the original version of grounded theory in his approach to data analysis. Strauss, along with Corbin (1990), revised the original version of grounded theory in their approach to data analysis, suggesting that engaging with literature could be explored before the study began, and argued that research questions and problems could be used in the method. Over time, grounded theory has evolved to produce several versions of the methodology, which are influenced by the individual researcher's epistemological beliefs. This study adopted Charmaz's (2000) 
constructivist grounded theory approach, which differs from the original grounded theory works proposed by Glaser, Strauss, and Corbin. Charmaz (2000) explains:

Unlike their position [Glaser and Strauss], I assume that neither data nor theories are discovered. Rather, we are part of the world we study and the data we collect. We construct our grounded theories through our past and present involvement and interactions with people, perspectives, and research practices (p.10).

The idea is that proposed interpretations of the studied phenomenon are not an exact replication of reality but a construct. To ensure that this construct accurately portrays participants' views and experiences, Charmaz (2000) suggests staying close to participants by keeping their words intact during analysis. Thus, Charmaz (2000) stresses that it is important to allow the research problem to be shaped by the method one adopts because it may help in choosing a method for data collection. In addition, researchers must familiarize themselves with the literature to engage in the ideas the grounded theory addresses and to analyze studies relating to the research problem and eventually the developed grounded theory.

The constructive grounded theory approach consists of "systematic, yet flexible guidelines for collecting and analyzing qualitative data to construct theories 'grounded' in the data themselves" (Charmaz, 2000, p.2). This approach complemented the research questions and offered guiding principles to accurately represent participants' views and experiences more appropriately than the grounded theory approaches proposed by Glaser and Strauss (2009). Six graduate students were interviewed about their experiences engaging in and witnessing the various learner-learner interactions in an online learning environment with the intention of developing a theory of the possible interactions that weaken students' sense of community.

\section{Participants and Content}

To gain a better understanding of the different types of learner-learner interactions that harmed students' sense of community, six students who had taken multiple online courses were interviewed about how they engaged with their peers in the online discussions through their online notes, which refer to students' postings in an online discussion (see Figure 2). Interestingly, some of these students mentioned that they were hesitant to take online courses because of the lack of social cues but that course content compelled them to enroll in the course. Overall, all participants emphasized that they had positive online learning experiences but emphasized that specific online interactions frustrated them. These students were full-time graduate students in the College of Education at a major North American university.

The online courses taken by the students all occurred over a 12-week period within an online learning environment called Pepper. Pepper is a web-based collaborative platform that offers a variety of knowledge-building applications and social networking tools to help students collaboratively share information, identify important ideas, and build on those ideas (see Figures 1 and 2). Stratification was also applied to the online courses to ensure that similar style courses were compared. For this study, seminar style courses were compared. 


\section{Introduction to Computers in Education}

\begin{tabular}{|l||l||l||l||l||l||l||l|} 
Home & Community & Messages & Preferences & Webinar & $\begin{array}{l}\text { Collective } \\
\text { Understanding }\end{array}$ & Administration & Windows $\mathbf{}$
\end{tabular}

\section{Home}

$\square$ Start Here
All About Us: Meet Our Class
Announcements
$\square \underline{\text { Class Lounge }}$
$\square \underline{\text { Questions and Answers }}$
$\square$ Sandbox
Webinars
$\square$ Week 1: Introduction
Week 2: Overview
$\square$ Week 3(a): From Incremental to Dramatic Effects
$\square$ Week 3(b): From Incremental to Dramatic Effects
$\square$ Week 4(a): Can Educational Technology Make a Difference?

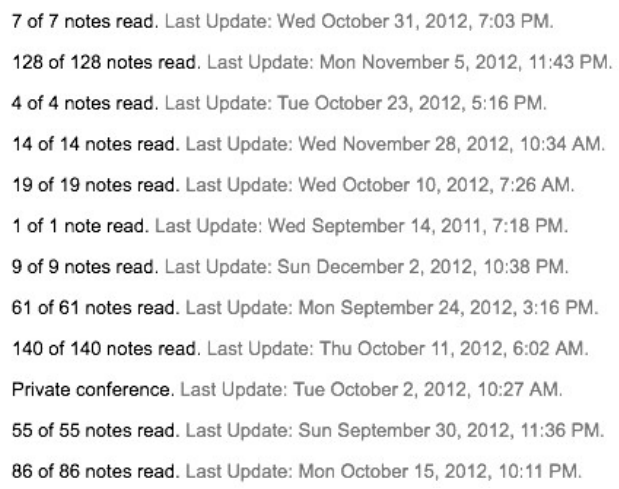

Figure 1. Example of an online graduate class in PeppeR

\section{Introduction to Computers in Education}

\begin{tabular}{|c|c|c|c|c|c|c|c|c|c|}
\hline Home & Community & Messages & Preferences & Webinar & $\begin{array}{l}\text { Collective } \\
\text { Understanding }\end{array}$ & Administration & Windows $\mathrm{v}$ & Lounge & Logout \\
\hline
\end{tabular}

\section{Week 4(a): Can Educational Technology Make a Difference?}

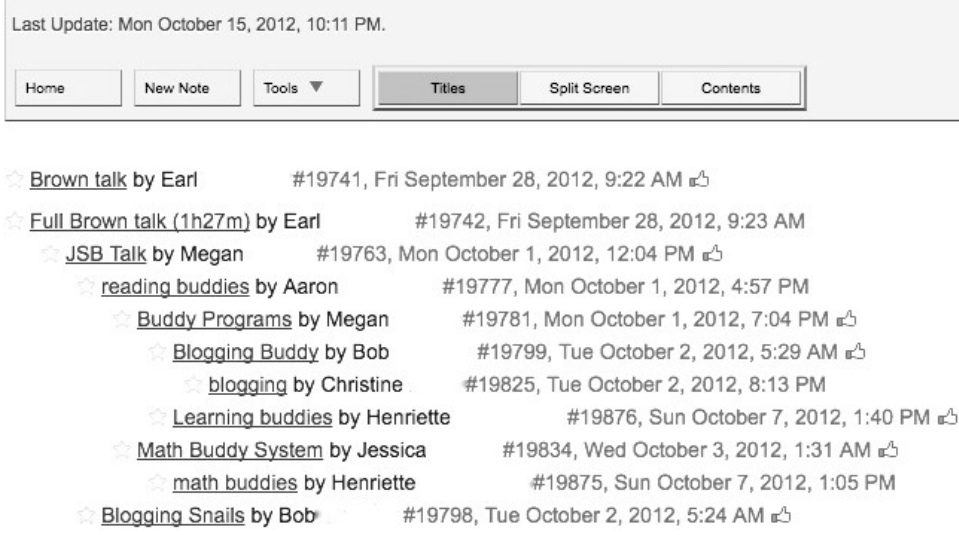

Figure 2. Example of online notes and the 'Like' button in an online discussion.

\section{Data Collection}

Participants were recruited using the convenience sampling method. (Glesne, 2011). All participants were students at the same College of Education attended by the researcher, were full-time graduate students, and had taken at least one online course. This particular sampling strategy was adopted because it allowed the researcher to select students who had the necessary 
experiences and insights to respond to the research questions. Data was collected during the spring academic semester of 2015. Hour-long, in-depth, semi-structured interviews were conducted with each participant, either face-to-face or through video chat, about the types of learner-learner interaction they witnessed and engaged in during their online courses. The interviews consisted of a set of open-ended questions to help guide the conversation, which allowed the researcher to probe and confirm when necessary.

Examples of questions used in the semi-structured interviews included the following: 1) Did you enjoy the online discussions? Why or why not? 2) What types of learner-learner interactions helped to foster or weaken a sense of community for you? and 3) Were there any learner-learner interactions that made you feel more connected or disconnected to your peers? How? Furthermore, these interviews followed a protocol in the guidelines suggested by Jacob and Furgerson (2012) which included: 1) reminding participants that their responses will be confidential, 2) notifying them that the interviews would be recorded, 3) stating the purpose of the research, 4) obtaining consent, and lastly, 5) conducting the interview with open-ended questions, which always started with basic background questions about the participant and always ended with letting them know the next steps of what they should expect after the interview. These next steps include: 1) transcribing the interview, 2) inviting participants to review the transcribed interview to ensure their views and experiences were accurately portrayed, and lastly, 3) reiterating to participants that that their confidentiality and privacy will be protected, especially when presenting their interviews at conferences and in publications. For the full interview protocol, please see Phirangee (2016). The interviews were transcribed verbatim to ensure that participants' views and experiences were accurately portrayed (Charmaz, 2000).

In addition, the convenience sampling method allowed the researcher to achieve the sample size in a timely and inexpensive manner (Marshall, 1996). However, it is important to emphasize that due to the small sample size and uncertainty about what population size would be representative, the findings cannot be generalized for the large population (Bryman, 2004). Yet, this study provides critical information on specific types of learner-learner interactions that weaken a sense of community for some online learners, thus leading them to feel isolated and disconnected from their peers. This information is helpful when trying to understand the reasons students decide to drop out from online courses.

\section{Data Analysis and Validation}

Each interview was analyzed thematically. This strategy involved searching the data for patterns and themes to generate insights about the research topic (Glesne, 2011), which required that the data be coded. Charmaz's (2014) coding method was followed in which she describes "[c]oding [as] the pivotal link between collecting data and developing an emergent theory to explain this data. Through coding, you define what is happening in the data and begin to grapple with what it means” (p. 46). For Charmaz (2014) coding consists of two phases. The first phase, "initial coding," involves skimming, reviewing, and highlighting words, phrases, and lines to identify a pattern. The second phase, "focused coding," involves selecting the codes that have extensive data support. During the second phrase, data are compared to other data, and then to codes to ensure that the appropriate code and theme is selected (Charmaz, 2014). For instance, 
similar focus codes with the most data support from each interview were selected and became the themes for this study. This will be further discussed in the results section. In addition, memowriting was also used to record those brief ideas about the codes which allowed this author to probe raw data more deeply and develop ideas earlier and more fully in the analytical process. Furthermore, Charmaz (2000) states that "when you bring raw data right into your memo, you preserve telling evidence for your analytic ideas from the start. Providing ample verbatim material 'grounds' your abstract analysis and lays a foundation for making claims about it" (p.82). Using focused coding and memo-writing validated that the most appropriate codes and themes, which represented all participants, were selected.

Furthermore, the inductive approach was adopted to identify themes because it is datadriven which means that the data was coded without forcing it to fit the researchers' biases based on familiarity with previous research (Braun \& Clarke, 2006). Using the inductive approach also further validated that appropriate themes were being selected without the researcher's biases. Lastly, the codes are semantic, which means they were identified based on what was written whereas themes reflect surface meanings of what the participant said and nothing more (Braun \& Clarke, 2006). This approach helped to again validate that appropriate themes were selected because it ensured that the researcher did not misinterpret or assume more than what the participants stated.

\section{Results}

Seven main themes emerged from data analysis, which revealed specific types of learnerlearner interactions that weakened a sense of community. Student insights revealed that these interactions negatively impacted their online learning experiences, eventually leading them to, at times, feel isolated and disconnected from their peers and the discussion. These seven themes are: the keener, lack of meaningful dialogue, selective listening, lack of attribution, going off on tangents, editing notes, and cultural exclusion.

\section{The Keener}

The "keener" moniker emerged from participants' description of peer behavior in online forums. For participants, the "keener" refers to peers who quickly and constantly respond to online notes, including discussions in which they are not a part. Although participants expressed happiness for their peers' excitement about the course, many revealed that they became frustrated and annoyed when their peers were too involved. Participants reported that "keener" involvement tended to dominate discourse and mute other voices. As one participant stated, "I'm not going to be super keener and respond to everything, it just doesn't seem genuine and that's annoying it takes away from the community because you start to question if what they're posting is real."

Similarly, another participant expressed her annoyance with the keener, emphasizing that this student took away from the discussion because one could not go deeper with ideas since this individual was always intervening. She states, 
There's the person who responds to everything in like 2 seconds, it's just a whole new level of keener and the thing is I consider myself pretty keen and then you see this person responding to everything, and everyone is just collectively thinking 'oh my gosh, I can’t [pause]. Is this all you're doing with your day, are you online 24/7,' even if they just respond 'thank you' or 'cool' or something fun, it's like they're always responding to everything and it's annoying because it doesn't seem genuine, it's too much. It would be like in a conversation where in a room and every single time someone said something I just interjected with 'thank you,' 'cool,' 'awesome' and nobody could have other conversations. I don't know I just feel like things like that just throw off the conversation, it's too distracting.

Dealing with the keener online seemed to be an overwhelming task. As one participant shared,

I mean for instance with the course that we did you could guarantee Monday morning or Tuesday morning or whenever it was, our keener peer, Marley [pseudonym], posted up 3 or 4 size bits of text full of references etc. and you think 'oh, okay well she's covered most bases there.' People would start tagging things onto that and I thought it was useful in some ways because I would read Marley's as a bit of a shortcut [laughs] and, you know, and then but I don't know, I don't know.

In summary, all participants expressed frustration with the keener because these students prevented their peers from developing deeper discussions about the course topics. Participants suspected that constant keener intervention was not genuine.

\section{Lack of Meaningful Dialogue}

With the limited social cues available online, participants revealed that they often adopted more friendly and positive language to avoid offending their peers. However, participants indicated that some of their peers overused such language, becoming overly nice by using such phrases as, "it was so wonderful to read your post" or "thanks very much for posting.” Such phrases sounded fake and were sometimes interpreted as insincere to students. As one participant stated,

If there's a lot of "good job,” "great," “that's awesome,” it’s like okay I know why you're doing this but you're hurting my eyeballs. I don't want to waste my time and read that stuff [laughs]. It just sounds fake to me because nobody in the real world says 'nice job' that many times. It's like a forced niceness and I found myself doing it, especially if everybody else was doing it because I felt like well in order to fit in I better type it in mine too. It's like I'm blunt, I'm a straightforward kind of person and sometimes people may take that the wrong way, so I changed how I expressed myself because I didn’t want people to get offended.

Similarly, another participant also shared concern about peers being overly nice, stating that it did not sound genuine and preferred positive phrases be used only when it was sincere. She states, 
To be honest I'm not going above and beyond but I do see people who in every single post they're responding to [pause], so it's hard to know if they're genuine. It's not my personality and I'm not going to go “oh, that's a wonderful idea.” I try to keep it for when it's meaningful so when I open my mouth to speak people listen. Instead of every single post being overly nice. So I posted when it was meaningful to myself or others could get something out of it.

Although participants acknowledged the reasons for using such niceties, many opted to avoid such language. For example, one participant stated,

I know from previous experience people and me too don't like the "yea, that's a great idea," "good job," or "thank very much for posting that," because it sounds fake, so I try to look and add to what people have to say, or maybe there was something in their post that reminded me of something that somehow relates to the course material that I could actually go to.

To summarize, participants acknowledged that being polite online was needed to some extent, especially with the limited social cues. However, participants became annoyed when their peers were overly nice because it seemed insincere in terms of avoiding meaningful dialogue, such as connecting with their peers or the course material because it required too much work. Therefore, participants emphasized that they tried not to be overly nice and opted to put energy into crafting a note that connected with their peers' ideas and the course content.

\section{Selective Listening}

Many instructors offer participation marks in hopes of motivating students to contribute to the online discussions. For participants, online notes are important because in the content of notes students usually share resources, negotiate ideas, and learn from each other's experiences. Therefore, it is critical that students respond to each other's notes because not doing so could be viewed as disrespectful. Participants also revealed that having their note ignored by their peers, or witnessing other peers' notes being ignored, meant that those particular notes were not valuable or needed for one's learning, which was hurtful. For instance, one participant stated,

Like there's nothing. I would put stuff out there and people just seem like [pause] they wouldn't know what to say. And at first, I took the onus 'hey maybe I need to make this more accessible' because it was like what am I doing wrong, and then I was like 'no their priority is them.' Like, their priority is their response, they're not looking to connect and understand I'm giving them ample to work with and I'm able to work with their stuff even though some of it is just so much navel-gazing.

Another participant shared an experience of a peer who sought responses from others in hopes of going deeper with the content but who was ignored. She states,

I noticed that one of the people [pause], she was actually placed in another group, and I could see her coming back to mine and commenting in my group a lot and I could see that she was waiting, she was waiting for other people to give her something to work on, to go deeper with, but nothing was happening. 
For some students, exposing their views, ideas, and experiences to other students' scrutiny requires courage. Therefore, the lack of response to postings might be viewed as rejection. For instance, a participant stated,

I felt nervous to post because I didn’t want to post and not have anybody respond to it. I would have felt uncomfortable and at the end of the day you sort of seek validation from your peers because when you put something up and when somebody doesn't reply it's sort of like "well that was a stupid idea. I shouldn't have put anything up.” It would have just felt like they didn’t respond because it wasn't worth responding to.

Overall, participants expressed discouragement when they perceived their notes were ignored or when they witnessed their peers' notes being ignored, and the belief that their peers were selectively listening to certain online discussions. For these participants, the effort, time, and courage required to post becomes invalidated when peers do not respond. When a note is perceived as being ignored participants revealed that it was personally hurtful to them because they felt as though their contributions were not helpful to their peers' learning.

\section{Lack of Attribution}

The number of notes produced in an online course can be overwhelming. At times, it can be difficult to keep track of who said what, leading to repetitive ideas within notes. Some participants expressed disappointment when one of their ideas was re-introduced into a discussion without receiving credit. For participants, not giving or receiving credit takes away from validation. Consider the following participant comment.

I think that when you're replying or if you're building on another person's note and you discover that your points have already been said, and if somebody included what you wanted to say in their post just take it from there, link back, acknowledge that person's work in your post, don't post the same thing. So, I think that it's really important to give credit to the person who came up with the idea first and it just makes people more comfortable.

Similarly, another participant expressed frustration with peers who merely repeated ideas rather than building on ideas already presented to develop a deeper understanding of the content. She states,

Some people are competing to write the best summary and it's like this is stupid I don't want to talk to any of you because you basically just copied what the next guy said but you've added an extra reference [laughs]. It's all about them; they don't care about others learning and want to explore the topic together. So, they're listening to respond not to build, or go deeper, or to help others. It's quantity over quality.

For many students, a quality note includes giving credit to others' ideas. Not doing so implies that one only cares about their own learning because there is no attempt to build on ideas and connect with others. As one participant states, 
So, it's quality over quantity. Just gets to be too much and you end up with like 500 post in a week and you can sift through it all but for me it's also like a visual overload. I rather quality notes because I'm getting something out of it. I'm getting credit, I'm getting to connect, and I'm getting new ideas. Quantity just seems like people are doing it to for show they just want the marks and could care less about actually relating to other people and connecting with the content.

In summary, participants expressed that it is important to give others credit for their ideas. Not doing so withholds much needed validation from their peers and gives the impression that one wants to steal credit instead of building on an idea in hopes of going deeper with it.

\section{Going off on Tangents}

Although some participants looked forward to reading their peers' online notes, others admitted that doing so was sometimes frustrating when peers went off on tangents in their notes. Such tangents might take the form of discussing unrelated topics or venting about an event or situation. Furthermore, participants emphasized that these tangents were distracting and, as a result, produced struggle in terms of response. For example, one participant stated,

I remember this one time when a peer asked me and vented about standardized testing, like thrashing it, and I thought okay [pause] and I found myself not replying, even though it was a peer I really liked to talk to and the thing is it was not the place to do this so I did not reply. But you know what she was comfortable enough to put that comment out there but I did not want to talk about standardized testing and so sometimes I would find myself not responding to thing that were not in line with the course. It's okay to bring up your feelings and personal experiences about a topic relating to the course but when it doesn't it's weird, it's going on a tangent, it's distracting.

Similarly, a participant expressed frustration about tangents, explaining that such behavior is distracting and only takes away from the discussion. She states, "I always try to keep my notes concise and focused because nobody wants to open up a note and it's super long because it's talking about so many different things. Nobody wants to be distracted by an unrelated note." Another participant vented about her peers who go on tangents, and having to respond to these notes because of mandatory note requirements implemented by her instructor. She states,

I think there's some students who post two weeks late for everything and write these long, confusing, and [pause] they're all over the place with their notes and it's like "what are you doing?" And at that point they just care about meeting the requirements...And for this course it was mandatory to respond to everyone who replied to your post and then you get someone like that, in the last week and now I have to respond to you.

Overall, participants found tangents frustrating, contributing additional stress to an already cognitively demanding environment. In addition, tangents are distracting and serve no purpose related to course content. 


\section{Editing Notes}

In the online learning environment, Pepper, students are able to edit their notes at any time. Many participants, especially those for whom English is a second language, expressed an appreciation for this feature because it allowed them to correct any typos or grammatical errors they may have missed after the note is shared publicly. However, participants emphasized that editing content in a note after a peer responded was wrong and should not be done because it would only cause problems. "That's cheating” as one participant declared, in reference to a note that was edited in such a way that the reply now seemed irrelevant and erroneous. Many participants felt that this type of interaction made the discussions awkward and decided not to communicate with peers who engaged in such behaviors. As one participant stated,

I don't really revise them because I feel like that's cheating. If you've written a note [pause], if it's a typo you're fixing that's one thing. I find this frustrating like someone wrote a note and I responded to it and then they revised it and included a paragraph which I commented on...so instead of responding to me they just added it into the original and then they were like 'oh, what were you talking about because I have it' and I was like 'what the heck' [pause], you revised it. So, I try to stay away from revising my posts after that because it was just a strange experience.

Similarly, other participants revealed that they edited their notes to fix grammatical errors and to make their notes clearer since they were English language learners but did not change the actual content of the note. As one participant stated, "after I post it, I rarely go back to check it, and revise it. So, usually I would revise any grammar or spelling mistakes especially since I'm an English language learner." The other English language learner stated, "because English is my foreign language, and I learn it as a foreign language sometimes I make spelling or typo mistakes. So, I like to check before and after I've posted it.”

To summarize, participants enjoyed having the option of editing their notes before and after it was posted publicly. However, they strongly emphasized that notes should be edited only for grammatical errors and not to change the content within a note, especially after a peer has replied. For participants, part of the learning process is to be challenged and to negotiate ideas presented, and avoiding such an experience is irresponsible. Therefore, when some students opted to avoid such learning experiences participants expressed frustration and admitted to loss of interest in the discussion. In other words, editing to correct grammatical errors was a widely accepted online behavior, but editing to change the content within a note was not accepted and weakened the online community by interrupting the learning process for students.

\section{Cultural Exclusion}

All participants expressed enjoyment when reading about their peers' personal experiences, especially when they were strongly connected to the course content, because they offered new perspectives to understand and explore the topic. Unfortunately, some participants revealed that they felt reluctant to share their cultural experiences because they did not know how to do so and feared not fitting in or being misunderstood. This assumption caused some participants to emotionally disconnect from the course and feel as though they did not contribute fully to the online discussions. For instance, a participant shared his peer's experience of feeling 
alienated in the online course stating,

She felt overwhelmed because of the activities, because of the discussions. She said sometimes the professor gave questions but people went off topic or they developed it in a certain way that she couldn't participate. So, this led me to think that perhaps the way we start online discussion might integrate as well as isolate some people...we didn't share the same experiences and in that sense she felt that she couldn't contribute anything valuable...So, when you have such a diverse population some people would be like the different ones and if they don't find a way to connect with the others in terms of, for example, personal interest, they will feel isolated and for them, community breaks down.

Similarly, another participant revealed that she did not share her cultural background because she did not think her peers would appreciate and understand it. She stated that “considering my cultural background of being from Kuwait [the Middle East], I don't know maybe I just didn't feel like people would get my experience and so it's just like why would I want to spend so much time anyways.” Another participant echoed a similar desire to share her cultural experience in relation to the course content but was reluctant to do so. She states,

Me being an Aboriginal person and working in an Aboriginal environment with mostly Indigenous post-secondary students and well in all of my classes I was the only one or there was one or maybe two other students that were Aboriginals, so a lot of the time I wanted to bring those examples into the classroom space because that's what I do, that's who I am, so it really [pause] I just tried to tie that in and make other students think along those lines because a lot of the times they did not, or they didn't know, or wouldn't want to think in that way, or didn't have any Aboriginal background or anything so that's what I tried do, that's what I wanted to do and sometimes it was hard to do but I tried.

To summarize, participants argued that when students do not feel welcome to share their cultural experiences in relation to the course content, they feel disconnected and isolated from their peers, the content, and the instructor. When students feel as though they are being excluded it implies that their experiences are less valuable but also does a disservice to their peers because they will miss out on reading about a new perspective.

\section{Discussion and Conclusion}

This study identified seven learner-learner interactions that students perceived to weaken their sense of community because it caused feelings of isolation and disconnection from their peers. These learner-learner interactions include: the keener, lack of meaningful dialogue, selective listening, lack of attribution, going on tangents, editing notes, and cultural exclusion. Furthermore, participants indicated that negative interactions with others affected their learning by causing them to avoid participation in the discussions.

More specifically, participants expressed their dislike for the keener simply because their behavior prevented others from having deeper discussions since they were constantly interrupting. Furthermore, participants also acknowledged that the keener online was different 
than one in a face-to-face class stating the online keener was constantly participating causing learners not only to be distracted but to also not get a chance themselves to share their view. This is an interesting finding, especially since previous literature suggests that there is no need for turn-taking in an online course because all learners can share and participate in many discussions (Hewitt, 2005), giving students more access to others' ideas. It appears that the ways the keener interacts are disruptive to their peers' learning because others do not have a chance to share their views and ideas at a deeper level. Such disruption not only annoys fellow students but also causes them to isolate the keener in hopes of protecting their learning goals and experiences.

Despite the lack of meaningful dialogue due to the overuse of niceties in online notes to prevent any misunderstandings between online learners, participants indicated that being too friendly and positive felt fake. As a result, many participants indicated that they became strategic when using such niceties so that it was more meaningful. This finding supports current literature in that those who are aware of the limited cues in online learning environments are more willing to invest time in crafting a response that minimizes potential misunderstandings yet reflects their emotion in the discourse (Derks, Fischer, \& Bos, 2008; Sherblom, 2010). Some students are aware of missing social cues and opt to compensate, possibly even over-compensate, for such cues by strategically using niceties in hopes of avoiding any misunderstandings, even if it means sounding fake and less meaningful. For example, as one participant stated above, "It's like I'm blunt, I'm a straightforward kind of person and sometimes people may take that the wrong way, so I changed how I expressed myself because I didn't want people to get offended.”

With regards to selective listening, participants emphasized that a lot of time and effort goes into crafting online notes in hopes of supporting their learning as well as their peers' learning. When a note is ignored some students develop the belief that their note was not valuable or helpful to the group discussion. Such beliefs may lead to feelings of disconnection and isolation; therefore validation from peers is critical in preventing or minimizing such feelings. This finding builds on a study conducted by Zembylas (2008) who found that some interactions could have a negative effect on students. For instance, an online note being ignored could lead students to believe that their contributions were not valuable to their peers' learning.

Participants also emphasized that the lack of attribution when re-introducing another peer's ideas is simply wrong. Not providing such validation will only disappoint students and cause them to become frustrated with contributing to an online discussion forum. In three recent studies (Makos, Oztok, Zingaro, \& Hewitt, 2013; Phirangee \& Hewitt, 2015; Phirangee, Demmans Epp, \& Hewitt, 2016) it was found that the 'Like' button was used to provide quick support for students' contributions (see Figure 2). Furthermore, students enjoyed receiving 'Likes' because it made them feel good about their contributions, thus providing that needed validation. In another study it was found "that acknowledgement, agreement, and approval are the glue that holds asynchronous discussion together” (Swan, 2002, p.41). Based on the insights from participants, students need to be given credit for their contributions because not doing so could have a negative effect on their online learning experience.

For participants, peers who go off on tangents within their online notes present challenges since their notes are distracting and off-topic. In addition, students struggle with how to respond to such notes since replying is mandatory at times, thus adding to their frustration. Going off on tangents may possibly cause students to become isolated in two ways. First, the tangent could 
simply be another strategic way for the creator of the note to insert and express emotion (Sherbolm, 2010), but doing so could cause other students to distance themselves from the creator of that note because they do not know how to connect with the tangent. Second, the creator of the note might think their contribution was not valuable if it receives no replies. (Zembylas, 2008). Either way, tangents are highly distractive and will only trigger feelings of frustration, according to participants.

Participants agreed that editing notes is allowed if the student plans to correct typos and grammatical errors, however the content of a note should not be edited after a peer has replied. For participants, editing the content of a note after a peer has replied is seen as shady because it implies that one does not want negotiate ideas. Moving ahead with editing the content of a note would only infuriate students and cause them to isolate and pull away from the person who has edited the content. This finding builds on Zembylas (2008) study of interactions that cause students to have negative experiences.

Finally when students feel culturally excluded because they do not feel comfortable in sharing their relevant cultural experiences, this devalues these students' experiences because it implies that one experience is more valuable and privileged than the other. This finding is supported by the literature. According to Gallagher and Savage (2013), online behaviors can differ between cultures, which can affect how motivated students are to participate in the community, what information and knowledge they share, and how cultures interpret online communication and privacy. Furthermore, this lack of sharing also prevents diverse knowledge pools from providing new perspectives of the course content. Such interactions could lead students to feel isolated and disconnected from their peers, the instructor, and course content. This finding supports Rovai and Wighting's (2005) study of a sense of community weakening for students who believe that their cultural and personal background would not be accepted by their peers, thus causing them to see themselves as different and eventually becoming isolated from others in the course.

In a traditional classroom-based course, many instructors have an idea of what types of interactions and strategies help meet learning objectives and support students' academic and social needs. However, online courses require a different style of teaching and some instructors may struggle with sorting out what strategies and interactions are effective in an online learning environment. Strategies and approaches used in face-to-face teaching may be less effective in online teaching. Understanding which interactions cause students to develop feelings of isolation and alienation could provide instructors with the opportunity to modify their instruction to counter such interactions by maintaining a strong sense of community for students. Doing so, may help to minimize the high attrition rates in online learning.

This research has identified seven specific learner-learner interactions that lead to feelings of isolation, alienation, and disconnection. Such feelings eventually weaken students' sense of community because it adversely affects learners' participation within an online course. Efforts to understand negative learner-learner interactions can help online instructors create guidelines for online discussion to better support their students in overcoming such interactions and hopefully lead to richer discussions.

Based on this study's findings, the following recommendations are offered to online 
instructors to address negative learner-learner interactions: 1) Create (or include) a section in the course syllabus that discusses netiquette for online discussions, 2) Adopt a facilitation role. Doing so allows the instructor to intervene and change the direction or tone of the discussion, 3) Offer students the opportunity to be discussion moderators. This allows students to not only be responsible for their learning but their peers’ learning as well.

\section{References}

Allen, I. E., \& Seaman, J. (2013). Changing course: Ten years of tracking online education in the United States. Sloan Consortium. PO Box 1238, Newburyport, MA 01950.

Angelino, L. M., Williams, F. K., \& Natvig, D. (2007). Strategies to engage online students and reduce attrition rates. Journal of Educators Online, 4(2), 1-4.

Arend, B. (2009). Encouraging critical thinking in online threaded discussions. The Journal of Educators Online, 6(1), 1-23.

Berge, Z. L., \& Muilenburg, L. (2002). Designing discussion questions for online, adult learning. In A. Rossett (Ed.), The ASTD E-learning handbook: Best practices, strategies and case studies for an emerging field (pp. 183-190). Chicago: McGraw-Hill Professional.

Bernard, R.M., Abrami, P.C., Lou, Y., Borokhovski, E., Wade, A., Wozney, L., Wallet, P.A., Fiset, M., Huang, B. (2004). How does distance education compare to classroom instruction? A meta-analysis of the empirical literature. Review of Educational Research, 74(3), 379-439.

Bolliger, D. U., \& Inan, F. A. (2012). Development and validation of the online student connectedness survey (OSCS). The International Review of Research in Open and Distance Learning, 13(3), 41-65.

Boston, W. E., Ice, P., Díaz, S. R., Richardson, J., Gibson, A. M., \& Swan, K. (2009). An exploration of the relationship between indicators of the community of inquiry framework and retention in online programs. The Journal of Asynchronous Learning Networks, 13(3), 67-82.

Braun, V., \& Clarke, V. (2006). Using thematic analysis in psychology. Qualitative research in psychology, 3(2), 77-101.

Bryman, A. (2004). Social Research Methods (2nd ed.). New York: Oxford University Press.

Carr, S. (2000). As distance education comes of age, the challenge is keeping the students. The Chronicle of Higher Education, 4(23), A39-A41.

Charmaz, K. (2014). Constructing grounded theory: A practical guide through qualitative analysis.

Thousand Oaks, CA: Sage Publications.

Conrad, D. (2005). Building and maintaining community in cohort-based online learning. Journal of Distance Education, 20(1), 1-20. 
Derks, D., Fischer, A. H., \& Bos, A. (2008). The role of emotion in computermediated communication: A review. Computer Human Behavior, 24, 766-785.

Diaz, D.P. (2002). Online drop rates revisited. The Technology Source, May/June. Retrieved from http://technologysource.org/article/online_drop_rates_revisited/

Drouin, M. A. (2008). The relationship between students' perceived sense of community and satisfaction, achievement, and retention in an online course. Quarterly Review of Distance Education, 9, 267-284.

Exter, M. E., Korkmaz, N., Harlin, N. M., \& Bichelmeyer, B. A. (2009). Sense of community within a fully online program: Perspectives of graduate students. Quarterly Review of Distance Education, 10, 177-194.

Fetzner, M. (2013). What do unsuccessful online students want us to know? Journal of Asynchronous Learning Networks, 17(1), 13-27.

Gallagher-Lepak, S., Reilly, J., \& Killion, C. (2009). Nursing student perceptions of community in online learning. Contemporary Nurse: A Journal for the Australian Nursing Profession, 32, 133-146.

Glesne, C. (2011). Becoming qualitative researchers: An introduction. Boston, MA: Pearson Education.

Glaser, B. G., \& Strauss, A. L. (2009). The discovery of grounded theory: Strategies for qualitative research. Transaction publishers.

Hara, N., \& Kling, R. (2001). Student distress in web-based distance education. Educause Quarterly, 24(3), 68-69.

Hewitt, J. (2005). Toward an understanding of how threads die in asynchronous computer conferences. The Journal of the Learning Sciences, 14(4), 567-589.

Hillman, D. C., Willis, D. J., \& Gunawardena, C. N. (1994). Learner-interface interaction in distance education: An extension of contemporary models and strategies for practitioners. American Journal of Distance Education, 8(2), 30-42.

Hirshhorn, R. (2011). Assessing the economic impact of copyright reform in the area of technology- enhanced learning. Retrieved from

http://www.ic.gc.ca/eic/site/ippd- dppi.nsf/eng/h_ip01074.html

Horspool, A., \& Lange, C. (2012). Applying the scholarship of teaching and learning: Student perceptions, behaviours and success online and face-to-face. Assessment \& Evaluation in Higher Education, 37(1), 73-88.

Hulon, S. (2013, March). Face-to-face discussions versus online threaded discussions: Can we have the best of both worlds? In Society for Information Technology \& Teacher Education International Conference (Vol. 2013, No. 1, pp. 577-582). 
Jacob, S. A., \& Furgerson, S. P. (2012). Writing interview protocols and conducting interviews: Tips for students new to the field of qualitative research. The Qualitative Report, 17(42), $1-10$.

Jaggars, S.S. \& Xu, D. (2010). Online learning in the Virginia Community College System. New York: Community College Research Center, Teachers College, Columbia University. $\quad$ Retrieved on June 4, 2011 from http://ccrc.tc.columbia.edu/Publication.asp?uid=813

Kanuka, H., \& Jugdev, K. (2006). Distance education MBA students: An investigation into the use of an orientation course to address academic and social integration issues. Open Learning, 21(2), 153-166.

Kelle, U. (2007). "Emergence" vs. "Forcing” of empirical data? A crucial problem of "Grounded Theory” reconsidered. Historical Social Research/Historische Sozialforschung. Supplement 6(2), 133-156.

Kelsey, K. D., \& D’souza, A. (2004). Student motivation for learning at a distance: Does interaction matter? Online Journal of Distance Learning Administration, 7(2), 1-10.

Larson, B. E., \& Keiper, T. A. (2002). Classroom discussion and threaded electronic discussion: Learning in two arenas. Contemporary Issues in Technology and Teacher Education, 2(1), 45- 62.

Layne, M., Boston, W., \& Ice, P. (2013). A longitudinal study of online learners: Shoppers, swirlers, stoppers, and succeeders as a function of demographic characteristics. Online Journal of Distance Learning Administration, 16(2).

Liu, X., Magjuka, R. J., Bonk, C. J., \& Lee, S. (2007). Does sense of community matter? Quarterly Review of Distance Education, 8, 9-24

Makos, A., Oztok, M., Zingaro, D., \& Hewitt, J. (2013, April). Use of a like button in a collaborative online learning environment. Poster presentation in the "online teaching and learning posters: Interaction and collaboration; social media and mobile approaches" session. American Education Research Association annual conference, April 26th-May 1st, 2013. Presented May 1st, 2013, San Francisco, CA, USA.

Marshall, M.N. (1996). Sampling for qualitative research. Family Practice, 13(6), 522-525

Moore, M. G., and Kearsley, G. (1996). Distance Education: A systems view. New York:

Wadsworth. Northrup, P. T. (2002). Online Learners’ Preferences for Interaction.

Quarterly Review of Distance

Education, 3(2), 219-26.

Ouzts, K. (2006). Sense of community in online courses. Quarterly Review of Distance Education, 7, 285-296. 
Phirangee, K. "Exploring the Role of Community in Online Learning." $\mathrm{PhD}$ dissertation, University of Toronto, 2016.

Phirangee, K., \& Hewitt, J. (2016). Loving this dialogue!!!! (:): Expressing emotion through the strategic manipulation of limited non-verbal cues in online learning environments. In S. Y. Tettegah \& M. P. McCreery (Eds.), Emotions, technology, and learning (pp. 69-85). New York: Elsevier.

Phirangee, K., Demmans Epp, C. D., \& Hewitt, J. (2016). Exploring the relationships between facilitation methods, students' sense of community and their online behaviours. Online Learning, 20(2), 1-21.

Reisetter, M., \& Boris, G. (2004). Student perceptions of effective elements in online learning.

Quarterly Review of Distance Education, 5(4), 277-291.

Rovai, A. P. (2002a). Building sense of community at a distance. The International Review of Research in Open and Distance Learning, 3(1), 1-16.

Rovai, A. P. (2002b). Sense of community, perceived cognitive learning, and persistence in asynchronous learning networks. Internet and Higher Education, 5(4), 319-332.

Rovai, A. P., \& Wighting, M. J. (2005). Feelings of alienation and community among higher education students in a virtual classroom. The Internet and Higher Education, 8(2), 97110.

Russell, T. L. (1999). The no significant difference phenomenon: A comparative research annotated bibliography on technology for distance education: As reported in 355 research reports, summaries and papers. North Carolina State University.

Sabry, K., \& Baldwin, L. (2003). Web-based learning interaction and learning styles. British Journal of Educational Technology, 34(4), 443-454.

Sharp, J. H., \& Huett, J. B. (2006). Importance of learner-learner interaction in distance education. Information Systems Education Journal, 4(46), 3-10.

Sherblom, J.C. (2010). The computer-mediated communication (CMC) classroom: A challenge of medium, presence, interaction, identity, and relationship. Communication Education, 59(4), 497-523.

Song, L., \& McNary, S.W. (2011). Understanding students' online interaction: Analysis of discussion board postings. Journal of Interactive Online Learning, 19(1), 1-14.

Stepich, D. A., \& Ertmer, P. A. (2003). Building community as a critical element of online course design. Educational Technology, 43(5), 33-43.

Strauss, A., \& Corbin, J. (1990). Basics of qualitative research (Vol. 15). Newbury Park, CA: Sage. 
Sutton, S. \& Nora, A. (2008). An exploration of college persistence for students enrolled in web- enhanced courses: A multivariate analytic approach. Journal of College Student Retention: Research, Theory \& Practice, 10(1), 21-37.

Swan, K. (Ed.). (2009). Threaded discussion. Encyclopedia of Distance Learning (2nd ed., Vols. 1-4).

Kent State University: IGI Global.

Swan, K. (2002). Building learning communities in online courses: The importance of interaction.

Education, Communication \& Information, 2(1), 23-49.

Thompson, T. L., \& MacDonald, C. J. (2005). Community building, emergent design and expecting the unexpected: Creating a quality e-learning experience. Internet and Higher Education, 8(3), 233-249.

Tu, C. H., \& McIsaac, M. (2002). The relationship of social presence and interaction in online classes. The American Journal of Distance Education, 16(3), 131-150.

Xenos, M., Pierrakeas, C. \& Pintelas, P. (2002). A survey on student dropout rates and dropout causes concerning students in the course of Informatics at Hellenic Open University. Computers and Education, 39, 361-377.

Xu, D. \& Jaggars, S.S. (2011). Online and Hybrid Course Enrollment and Performance in Washington State Community and Technical Colleges (CCRC Working Paper No. 31). New York: Community College Research Center, Teachers College, Columbia University. Retrieved from http://ccrc.tc.columbia.edu/Publication.asp?UID=872

Zembylas, M. (2008). Adult learners' emotions in online learning. Distance Education, 29(1), 7187.

Zheng, L., \& Smaldino, S. (2003). Key Instructional Design

Elements for Distance Education. Quarterly Review of Distance Education, 4(2), 153-66. 